\title{
AVALIAÇÃO DA ALIMENTAÇÃO FORNECIDA EM UMA UNIDADE DO SISTEMA PRISIONAL DO ESTADO DE MINAS GERAIS
}

Evaluation of supply food in a unit of the prison system of the state of Minas Gerais.

\author{
Camila Pereira de Souza ${ }^{1}$, Vanessa Fernandes Coutinho ${ }^{2}$, Renato Ribeiro Nogueira Ferraz ${ }^{3}$ \\ ${ }^{1-3}$ Universidade Estácio de Sá - SP.
}

\section{RESUMO}

Este estudo teve como objetivo avaliar a qualidade nutricional fornecida em uma unidade do sistema prisional do estado de Minas Gerais. Estudo em caráter retrospectivo, descritivo, com abordagem qualitativa, composto por 15 cardápios. A análise dos cardápios foi realizada com auxílio de um programa editor de planilhas, onde foram analisados o valor calórico total e a porcentagem de carboidrato, proteína e lipídeos, fibras, cálcio, ferro, vitamina $\mathrm{C}$ e vitamina $\mathrm{A}$. Todos os cardápios analisados apresentaram o percentual de carboidrato, proteína e fibras adequados ao valor recomendado. O consumo diário de lipídeos apresentou-se ideal em $80 \%$ dos cardápios analisados. O cálcio, vitamina $\mathrm{C}$ e $\mathrm{A}$ não apresentaram adequação das recomendações em mais de $50 \%$ dos cardápios. Considerando que $93,75 \%$ dos presos são homens, o teor de ferro se apresenta dentro do recomendado, porém apresenta-se abaixo para as mulheres. Conclui-se que as vitaminas $\mathrm{A}$ e $\mathrm{C}$ apresentaram-se abaixo do valor recomendado pela DRIS, favorecendo assim um risco nutricional, havendo uma necessidade de uma melhor elaboração dos cardápios, visando à melhoria da qualidade de vida dos comensais.

Palavras-chave: Nutrição. Saúde coletiva. Alimentação. Cardápio.

\begin{abstract}
This study there was a means to evaluate the nutritional quality provided on a unity of the prison system on the States of Minas Gerais. The study in retrospective character, descriptive with the quality approach, composted by 15 menus. The menus analysis was performed with an auxiliary spreadsheet edit program, where were analyzed the total caloric value and the percentage of carbohydrate, protein and lipids, fiber, calcium, iron, $\mathrm{C}$ and A vitamin. All the menus analyzed introduce the appropriated percentage of the recommended value from carbohydrate, protein, and fibers. The Daily consumption of the lipids proved to be efficient in $80 \%$ of the analyzed menus. The calcium, $\mathrm{C}$ and $\mathrm{A}$ vitamin did not present of the recommendation at more the $50 \%$ of the menus. Considered $93.75 \%$ of the prisoners are men, the iron content is within the recommended range, however, presented below for the women. Concludes that the A and $\mathrm{C}$ vitamin presented below of the recommended value of the DRIS, favoring a nutritional risk, there is a need for a better elaboration of the menus, aims to improve the life quality of the diners.
\end{abstract}

Keywords: Nutrition. Collective health. Food. Menu.

\section{INTRODUÇÃO}

Os direitos humanos preveem uma alimentação adequada tanto em qualidade quanto em quantidade, garantindo a Segurança Alimentar Nutricional (SAN) e o direito à vida. A SAN representa a concessão do direito ao acesso regular e permanente a alimentos de qualidade a todos os cidadãos, em quantidade suficiente e sem comprometer outras necessidades essenciais (CFN, 2010). O nutrólogo argentino, Pedro Escudero, propôs as leis fundamentais da alimentação. Essas regras possibilitam uma alimentação adequada a todos os indivíduos: a quantidade de alimentos deve ser suficiente para atender as necessidades do organismo, deve 
ter qualidade para oferecer todas as substâncias necessárias e, os muitos nutrientes que integram a alimentação, devem ter uma relação de proporção entre si (GUIMARÃES; GALISA, 2008).

A alimentação para os presidiários é de extrema importância, tendo estes, o direito a uma alimentação de qualidade, cujo valor nutritivo seja suficiente para a manutenção da saúde e de sua energia física (THOMÉ et al, 2016). No Sistema Prisional do Estado de Minas Gerais, o fornecimento das refeições é realizado por empresas privadas, através de contratos. A Secretaria do Estado de Defesa Social (SEDS) realiza, através de nutricionistas, visitas técnicas periódicas, para fiscalizar os locais onde as refeições são preparadas e o cumprimento das cláusulas contratuais (SEDS, 2013). Nas unidades prisionais de Minas Gerais são servidas quatro refeições, sendo elas: desjejum, almoço, lanche da tarde e jantar. Os cardápios são analisados pelo Núcleo da Subsecretaria de Inovação e Logística (SULOG) da SEDS, sendo verificada a incidência dos alimentos e nutrientes, e qualquer alteração deve ser notificada e autorizada pela SEDS (SEDS, 2013).

Cada macronutriente, vitamina e mineral tem uma função metabólica no organismo. O carboidrato é responsável por produzir energia para as células, principalmente do cérebro. Os lipídeos, maior fonte de energia do organismo, são necessários para a absorção de vitaminas lipossolúveis e carotenoides. A proteína é responsável pelo equilíbrio de nitrogênio do organismo, o gasto com a formação de tecidos e secreção láctea, no caso de gestantes (FRANCESCHINI; PRIORE; EUCLYDES, 2005). Segundo a IOM 2002/2005, as recomendações nutricionais (Recommended Dietary allowances - RDA) dos macronutrientes são determinadas considerando-se o percentual de cada um em relação ao requerimento energético total, com o objetivo de prevenir doenças crônicas não-transmissíveis (VITOLO, 2008). Os macronutrientes devem estar em uma faixa de distribuição adequada em relação ao valor energético total (VET). O recomendado é de 45 a $65 \%$ de carboidrato do VET, de 10 a $35 \%$ de proteína e de 20 a 35\% de lipídeos (IOM, 2002/2005).

A fibra solúvel aumenta o tempo do trânsito intestinal, diminuindo, assim, o esvaziamento gástrico, a absorção da glicose, a glicemia pós-prandial e o colesterol sanguíneo. A fibra insolúvel contribui para o aumento do volume fecal, reduz o tempo de trânsito intestinal, retardo da absorção de glicose e retardo da hidrólise do amido (CATALANI et al, 2003). A recomendação de fibras totais, que é a soma da fibra solúvel com a fibra insolúvel, pode ser expressa como sendo 25g/dia para mulheres e de 38g/dia para os homens (VITOLO, 2008).

O cálcio está ligado à formação de ossos e dentes, participa do crescimento do indivíduo e é um cofator/regulador de várias reações bioquímicas (BELARMINO et al, 2005). O ferro tem diversas funções importantes no organismo, entre elas está o transporte de oxigênio e dióxido de carbono e o funcionamento do sistema imunológico (CARVALHO, BARACAT, SGARBIERI, 2006). As recomendações de cálcio e ferro, segundo a DRIS (1997/2000), são 1000 a $1200 \mathrm{mg} /$ dia e $6 \mathrm{mg} /$ dia, respectivamente.

A vitamina $\mathrm{C}$ possui diversas funções metabólicas, dentre elas destaca-se a atuação como antioxidante e biossintetizador de aminoácidos e de colágeno, sua recomendação pela DRIS é de $75 \mathrm{mg} /$ dia para homens e $90 \mathrm{mg} /$ dia para mulheres. A vitamina A é importante para a reprodução, a visão e a resposta imunológica, a DRIS recomenda que sua ingestão diária seja de $900 \mu \mathrm{g}$ RE para homens e $700 \mu \mathrm{g}$ RE para mulheres (FRANCESCHINI; PRIORE; EUCLYDES, 2005).

As alterações no cardápio são possíveis mesmo após o planejamento do mês. Perante as exigências da SEDS e as recomendações diárias, é importante a avaliação dos cardápios analisando a distribuição de macro e micronutrientes, visando fornecer informações que poderão ser utilizadas para fornecer uma melhor qualidade de vida dos presidiários, ao menos em relação ao aporte nutricional.

\section{OBJETIVO}


Avaliar a alimentação fornecida em uma unidade do sistema prisional do Estado de Minas Gerais para certificar se os comensais estão recebendo os valores energéticos necessários.

\section{MÉTODO}

A pesquisa realizada foi de caráter retrospectivo, descritivo, com abordagem qualitativa, realizado na unidade prisional da cidade de Pouso Alegre, no Sul de Minas Gerais. Esta pesquisa foi baseada na avaliação dos cardápios entre os meses de abril e julho de 2017. No período de realização do estudo, a unidade prisional possuía, aproximadamente, 800 presos, sendo servidas a eles quatro refeições: desjejum, almoço, lanche da tarde e jantar; sendo preparadas, porcionadas e distribuídas por uma empresa terceirizada. Cada refeição servida possuía um porcionamento exigido pela SEDS, no qual devia ser cumprido em cada marmita/refeição montada, assim todos os presos recebiam exatamente a mesma quantidade de alimentos. Através dessas informações foram calculados os cardápios diários, conforme Tabela 1 .

Tabela 1 - Porção individual dos alimentos servidos na Unidade Prisional de Pouso Alegre MG

\begin{tabular}{lc}
\hline \multicolumn{1}{c}{ Alimento } & Gramas/mililitros \\
\hline Café & $100 \mathrm{ml}$ \\
Leite & $200 \mathrm{ml}$ \\
Pão doce / salgado & $50 \mathrm{~g}$ \\
Margarina & $10 \mathrm{~g}$ \\
Folhas (salada) & $30 \mathrm{~g}$ \\
Legumes ralados & $40 \mathrm{~g}$ \\
Legumes cozidos & $45 \mathrm{~g}$ \\
Tomate, pepino, vinagrete & $60 \mathrm{~g}$ \\
Saladas mistas & $80 \mathrm{~g}$ \\
Arroz & $300 \mathrm{~g}$ \\
Feijão (simples, tropeiro, tutu) & $150 \mathrm{~g}$ \\
Feijoada & $235 \mathrm{~g}$ \\
Prato principal (carnes) & $85 \mathrm{~g}$ \\
Massas (incluindo lasanhas) & $120 \mathrm{~g}$ \\
Farofa & $80 \mathrm{~g}$ \\
Outras guarnições & $100 \mathrm{~g}$ \\
Suco & $300 \mathrm{ml}$ \\
Frutas & $1 \mathrm{unidade}$ \\
Frutas porcionadas & $120 \mathrm{~g}$ \\
Doces tabletes & $1 \mathrm{unidade}$ \\
Pudim e gelatina & $80 \mathrm{~g}$ \\
\hline
\end{tabular}

Fonte: Dados contratuais (2017).

Para a análise nutricional dos cardápios foram calculados a porcentagem de carboidrato, proteína e lipídeos, fibras, cálcio, ferro, vitamina C e vitamina A. Os cardápios foram calculados com auxílio de um editor de planilhas. Para a consulta da composição de alimentos de parte comestível foi utilizada a Tabela Brasileira de Composição de Alimentos (TACO) de 2011, na ausência de alimentos na tabela, ou de alimentos específicos, foram consultados os rótulos dos alimentos. 
Foram considerados os Valores de Ingestão Dietética de Referência (Dietary Reference Intakes - DRIS) para a avalição dos micronutrientes (IOM, 1997) e da IOM (2002/2005) para os macronutrientes. As variáveis foram apresentadas pelos seus valores médios \pm desvio padrão.

No café da manhã servia-se café, leite e pão de sal com margarina. No almoço distribuíase uma marmita de salada, podendo ser uma salada mista - como macarrão temperado ou mista de legumes - ou uma salada em folha, com algum tipo de legume ou fruto; uma marmita quente de arroz, feijão, prato principal e guarnição, acompanhado de uma sobremesa (fruta, doce, pudim ou gelatina). Pão doce com margarina e suco eram servidos no café da tarde. No jantar servia-se uma marmita quente do mesmo modo como no almoço, mas acompanhado apenas por uma fruta, podendo ser porcionada ou unidade.

O cardápio é elaborado pela nutricionista responsável pelo planejamento na sede central em Belo Horizonte - MG, e encaminhado para cada unidade para realizar adequações, de acordo com a aceitação dos comensais. Após as modificações, o novo cardápio é encaminhado para a SEDS, para aprovação da nutricionista fiscal. Após acompanhar a elaboração e a produção dos cardápios, pode-se observar que, na unidade de Pouso Alegre - MG, as restrições e alterações dos cardápios são frequentes, fazendo questionar-se as necessidades nutricionais da população estão sendo atingidas.

\section{RESULTADOS}

No presente estudo, foram analisados 15 cardápios, selecionados aleatoriamente, em dois meses distintos, sendo 53,3\% (n=8) do mês de abril de 2017 e 46,7\% (n=7) do mês de julho de 2017. A Tabela 2 apresenta os valores mínimo, máximo, média \pm desvio padrão dos macronutrientes analisados, que foram apresentados em porcentagem, e dos micronutrientes, apresentados em gramas $(\mathrm{g})$, miligramas $(\mathrm{mg})$ ou microgramas $(\mu \mathrm{g})$.

Tabela 2 - Análise descritiva das variáveis estudadas.

Fonte: Dados do autor (2018).

\begin{tabular}{lllll} 
Nutrientes & Mínimo & Máximo & Média & Desvio Padrão \\
\hline Carboidrato $(\%)$ & 57,17 & 65,40 & 62,14 & 2,08 \\
Proteína $(\%)$ & 13,07 & 18,17 & 16,16 & 1,55 \\
Lipídeos $(\%)$ & 16,88 & 27,90 & 21,70 & 2,88 \\
Fibras $(\mathrm{g})$ & 43,66 & 50,54 & 46,79 & 1,98 \\
Cálcio $(\mathrm{mg})$ & 436,39 & 593,80 & 487,11 & 47,51 \\
Ferro $(\mathrm{mg})$ & 8,14 & 13,31 & 11,33 & 1,32 \\
Vitamina C $(\mathrm{mg})$ & 7,71 & 155,51 & 51,74 & 54,79 \\
Vitamina A $(\mu \mathrm{g} \mathrm{RE})$ & 141,75 & 186,15 & 157,82 & 18,23 \\
\hline
\end{tabular}

Pode-se observar que a média de porcentagem de carboidrato em relação ao valor energético total (VET) nos cardápios foi de $62,14 \pm 2,08 \%$, o mínimo de $57,17 \%$ e o máximo de $65,40 \%$. A porcentagem de proteína mínima apresentada foi de $13,07 \%$ e máxima 18,17 ; já a média foi de $16,16 \pm 1,55 \%$. O lipídeo apresentou uma média de $21,70 \pm 2,88 \%$; o máximo de $27,90 \%$ e o mínimo de $16,88 \%$. Os micronutrientes fibras, cálcio, ferro, vitamina C e vitamina A apresentaram uma média de 46,79 $\pm 1,98 \mathrm{~g}, 478,11 \pm 47,51 \mathrm{mg}, 11,33 \pm 1,32 \mathrm{mg}$, $51,74 \pm 54,79 \mathrm{mg}, 157,82 \pm 18,23 \mu \mathrm{g}$ RE, respectivamente. O valor mínimo e máximo de fibras, cálcio, ferro, vitamina C e vitamina A encontrados foram de 43,66g e 50,54g, 436,39mg e $593,80 \mathrm{mg}, 8,14 \mathrm{mg}$ e $13,31 \mathrm{mg}, 7,71 \mathrm{mg}$ e $155,51 \mathrm{mg}, 141,75 \mu \mathrm{g}$ RE e $186,15 \mu \mathrm{g}$ RE, respectivamente.

\section{DISCUSSÃO}


Todo alimento fornece nutrientes, os macro e micronutrientes, que possuem funções específicas no organismo e atuam no metabolismo de formas diferentes (PAREDES, 2005). As recomendações dos alimentos que podem ser servidos em uma unidade prisional de Minas Gerais, são específicas, assim como a gramagem fornecida.

Analisando o percentual de carboidrato e proteína dos cardápios observou-se que todos obtiveram um valor adequado do recomendado. Os valores recomendados seria de 45 a $65 \%$ de carboidrato e de 10 a 35\% de proteína, segundo IOM (2002/2005). Considerando os lipídeos, a minoria apresentou valores abaixo do recomendado ao valor recomendado, que seria de 20 a 35\% (IOM, 2002/2005). No estudo feito por Souza, Silva e Fernandes (2009) para avaliar os cardápios de cinco refeitórios do município de Caruaru, em Pernambuco, usando como parâmetro o Programa de Alimentação do Trabalhador, observaram que os cardápios foram inadequados, sendo encontrada uma média de 75,4\% para calorias (recomendado de 30 a 40\%), 90,33\% de carboidrato, a média do total de proteína oferecida foi de $38,48 \%$ e $57,21 \%$ de lipídeos, todos os padrões analisados apresentaram-se acima do recomendado.

A ingestão adequada de fibras foi determinada como sendo de $25 \mathrm{~g} /$ dia para mulheres e de 38g/dia para os homens (VITOLO, 2008). As fibras apresentaram valores adequados ao recomendado (IOM, 2002/2005).

Segundo os Valores de Ingestão Dietética de Referência (Dietary Reference Intakes DRIS) a recomendação de cálcio diário para adultos é de 1000 a $1200 \mathrm{mg} /$ dia, para adultos e idosos de ambos os gêneros. Observou-se neste estudo que o consumo diário de cálcio dos presidiários está abaixo do ideal recomendado, não atingindo a necessidade diária (IOM, 1997).

O teor de ferro encontrado após a avaliação dos cardápios apresentou valores adequados ao recomendado que seria de $6 \mathrm{mg} /$ dia para homens (FRANCESCHINI; PRIORE; EUCLYDES, 2005), considerando que $93,75 \%$ dos presos desta unidade são homens. Para suprir a necessidade de $6,25 \%$ de mulheres residentes nesta unidade prisional, os valores recomendados apresentam-se inadequado.

Analisando o percentual de vitamina $\mathrm{C}$ observou-se que apenas a minoria dos cardápios apresentou-se dentro do valor recomendado, estando a maioria abaixo do recomendado pela DRIS. A recomendação da vitamina C pela DRIS é de $75 \mathrm{mg}$ para homens e $90 \mathrm{mg}$ para mulheres (LUFT et al, 2008). A vitamina A apresentou-se abaixo da ingestão diária adequada, encontrando-se uma média de 157,82 $\pm 18,23 \mu \mathrm{g}$ RE, sendo que o recomendado pela DRIS seria de $900 \mu \mathrm{g}$ RE para homens e $700 \mu \mathrm{g}$ RE para mulheres (LUFT et al, 2008). Sousa, Marques e Vasconcelos (2014) investigaram a qualidade nutricional em relação a oferta de micronutrientes dos cardápios oferecidos aos idosos de uma instituição de longa permanência em Teresina de Piauí, os resultados apresentaram valores acima do recomendado pela DRIS, sendo encontrados $2880 \mu \mathrm{g}$ RE de vitamina A, $559 \mathrm{mg}$ de vitamina C e 1510,92 mg de cálcio.

\section{CONCLUSÃO}

Os cardápios analisados na Unidade Prisional apresentaram valores de macronutrientes, fibra, cálcio e ferro adequados com os recomendados. Porém, as vitaminas A e C apresentaramse abaixo do valor recomendado pela DRIS, favorecendo assim um risco nutricional, especialmente relacionado a antioxidante e biossentizador de aminoácidos e colágenos, à visão e a resposta imunológica. A partir dos dados apresentados sugere-se analisar constantemente o cardápio de unidades prisionais, a fim de garantir o suprimento adequado em quantidade e qualidade dos alimentos. Por fim, recomenda-se a realização de novos estudos com maior duração, para avaliar se os resultados aqui observados poderão se repetir quando avaliados em maior escala.

\section{REFERÊNCIAS}


BELARMINO, A. C. et al. Avaliação do consumo de cálcio em mulheres saudáveis. Revista Uniara, n. 16, p. 203-212, 2005.

CARVALHO, M. C.; BARACAT, E. C. E.; SGARBIERI, V. C. Anemia Ferropriva e Anemia de Doença Crônica: Distúrbios de Metabolismo de Ferro. Segurança Alimentar e Nutricional, v. 13, n. 2, p. 54-63, 2006.

CATALANI, L. A. et al. Fibras Alimentares. Revista Brasileira de Nutrição Clínica, v. 18, n. 4, p. 178-182, 2003.

CONSELHO FEDERAL DE NUTRICIONISTAS. Compromissos do nutricionista com o direito humano à alimentação. 2010. Disponível em "http://www.cfn.org.br/novosite/arquivos/direito_humano_banner.pdf”. Acessado em 27/09/2017.

FRANCESCHINI, S. C. C.; PRIORE, S. E.; EUCLYDES, M. P. Necessidades e Recomendações de Nutrientes. In: Cuppari L. Nutrição clínica no adulto. 2a ed. São Paulo: Manole; p. 3-32, 2005.

GUIMARÃES, A. F.; GALISA, M. S. Cálculos Nutricionais: Conceitos e Aplicações Práticas. São Paulo: M. Books do Brasil Editora LTDA, 2008.

INSTITUTE OF MEDICINE (IOM). Dietary reference intakes for calcium, phosphorus, magnesium, vitamin D and fluoride. Washington, D. C.: National Academy Press, 1997, 432 p. INSTITUTE OF MEDICINE (IOM). Dietary reference intakes for energy, carbohydrate, fiber, fat, fatty acids, cholesterol, protein and aminoacids. Washington, D. C.: National Academy Press, 2002/2005, p. 1331.

LUFT, V. C. et al. Suprimento de micronutrientes, adequação energética e progressão da dieta enteral em adultos hospitalizados. Revista de Nutrição, Campinas, v. 21, n. 5, p. 513-523, 2008. PAREDES, L. C. Avaliação do Alimentação terceirizada no sistema penitenciário do Paraná. 2005. 43f. Monografia (Pós-Graduação) - Administração em Saúde Pública; Instituto Superior de Ensino, Pesquisa e Extensão, 2005.

SECRETARIA DO ESTADO DE DEFESA SOCIAL (SEDS). Contratualização de níveis de serviços e fiscalização por verificador independente para contratos de fornecimentos de alimentação para unidades prisionais e socioeducativas. Belo Horizonte, 39p, 2013. Disponível em

http://www.ppp.mg.gov.br/images/documentos/Projetos/em_elaboracao/Alimentacao_Prision ais/Consulta\%20Publica\%20-\%20Alimentacao\%20SEDS.pdf . Acessado em 05/10/2017.

SOUSA, F. A.; SILVA, R. C. O.; FERNANDES, C. E. Avaliação nutricional de cardápios em unidades de alimentação e nutrição: adequação ao programa de alimentação do trabalhador. Revista Eletrônica de Ciências, Ipojuca, v. 2, n. 1 e 2, p. 43-50, 2009.

SOUSA, M. O.; MARQUES, M. P.; VASCONCELOS, S. M. Análise de cardápios oferecidos à idosos residentes em instituição de longa permanência. Revista Interdisciplinar, São Cristóvão, v. 7, n. 1, p. 1-7, 2014.

TABELA BRASILEIRA DE COMPOSIÇÃO DE ALIMENTOS. UNICAMP - 4. ed. rev. e ampl. Campinas: NEPA/UNICAMP, 2011, $161 \mathrm{p}$.

THOMÉ, B. et al. Qualidade da alimentação fornecida em uma unidade do sistema penitenciário do estado do Pará. Revista Biosaúde, Londrina, v. 18, n. 2, p. 75-81, 2016.

VITOLO, M. R. Especifidades dos Nutrientes. In: Vitolo, M. R. Nutrição da Gestação ao Envelhecimento. 6a ed. Rio de Janeiro: Editora Rubio LTDA; p. 17-34, 2008. 